\title{
Omalizumab in Children
}

\author{
Amelia Licari · Alessia Marseglia $\cdot$ Silvia Caimmi · \\ Riccardo Castagnoli • Thomas Foiadelli • \\ Salvatore Barberi · Gian Luigi Marseglia
}

Published online: 18 November 2014

(c) The Author(s) 2014. This article is published with open access at Springerlink.com

\begin{abstract}
Omalizumab is a recombinant humanized monoclonal antibody that reduces levels of circulating immunoglobulin $\mathrm{E}$ ( $\mathrm{IgE}$ ) and expression of $\operatorname{IgE}$ highaffinity receptors on mast cells and basophils, interrupting the subsequent allergic inflammatory cascade. Current indications for treatment with omalizumab in pediatric patients are clearly defined and are confined to moderateto-severe uncontrolled allergic asthma and chronic spontaneous urticaria (CSU). Any other prescription can only be off label. Data available from clinical trials conducted in children suggest that omalizumab is clinically effective and generally well tolerated. Given its mechanism of action, recent reports have suggested its possible clinical use in other IgE-mediated disorders, such as allergic rhinitis, food allergy, and anaphylaxis. In recent years, several studies have also investigated the possible applications of omalizumab in a number of non IgE-mediated diseases. The aim of the present review is to assess all applications of omalizumab as therapy in the pediatric population. The approved indications-allergic asthma and CSU-are reviewed. Moreover, further potential applications of omalizumab are discussed in both IgE-mediated and nonIgE-mediated diseases.
\end{abstract}

A. Licari - A. Marseglia - S. Caimmi - R. Castagnoli ·

T. Foiadelli · G. L. Marseglia ( $₫)$

Department of Pediatrics, University of Pavia, Fondazione

IRCCS San Matteo, Pavia, Italy

e-mail: gl.marseglia@smatteo.pv.it

S. Barberi

Department of Pediatrics, San Paolo Hospital, University of Milan, Milan, Italy

\section{Key Points}

Omalizumab is a monoclonal antibody that targets circulating free immunoglobulin $\mathrm{E}$ (IgE) and prevents its interaction with the high-affinity $\operatorname{IgE}$ receptor (FcERI), thereby interrupting the allergic cascade.

Current indications for treatment with omalizumab are confined to moderate-to-severe uncontrolled allergic asthma and chronic spontaneous urticaria. Any other prescription can only be off label.

Data available from clinical trials conducted in pediatric populations suggest that omalizumab is generally well tolerated.

\section{Introduction}

Omalizumab is a recombinant DNA-derived humanized monoclonal antibody. It is an immunoglobulin $\mathrm{E}$ (IgE)specific, IgG1 $\kappa$ antibody that targets circulating free IgEs [1].

Discovered in 1966 by Ishizaka, IgE antibodies play a crucial role in the pathophysiology of allergic disease. Once produced and released into the bloodstream, $\operatorname{IgE}$ molecules bind to high-affinity and low-affinity receptors for the Fc region of IgE (Fc\&RI and FceRII, respectively) on the surface of tissue mast cells and circulating basophils [2]. The binding between allergens and allergen-specific IgEs on the surface of these cells leads to rapid release of preformed mediators, including histamine, proteoglycans, and proteases, transcription of cytokines (interleukin [IL]4, tumor necrosis factor [TNF], IL-6), and de novo 
synthesis of prostaglandins (PGD2) and leukotrienes (LTD4), thus resulting in clinical manifestations of type I hypersensitivity and promotion of adhesion and infiltration of circulating inflammatory cells [2].

Considering the pivotal mechanism of action of $\operatorname{IgE}$ antibodies in allergy, it is clear that anti-IgE therapy could represent an effective treatment for several allergic diseases.

In particular, omalizumab decreases levels of circulating $\operatorname{IgE}$ by binding to the constant region (CE3) of the $\operatorname{IgE}$ molecule, which prevents free $\mathrm{IgE}$ from interacting with high-affinity and low-affinity IgE receptors (FceRI and FceRII) [1]. The reduction of free IgE levels following omalizumab administration leads to a downregulation of FceRI expression on inflammatory cells [1]. In addition, it has been demonstrated that omalizumab also reduces FceRI in vivo expression on dendritic cells, which may lead to a reduction in allergen presentation to $T$ cells and attenuation in the $\mathrm{Th}_{2}$-mediated allergic pathway [3]. Thanks to these effects, omalizumab decreases proinflammatory mediator release, thus reducing allergic inflammation [4]. In particular, treatment with omalizumab decreases mast-cell activation and sensitivity and reduces eosinophil infiltration and activation $[4,5]$. All the effects described represent the biological basis for treatment with omalizumab and justify its clinical efficacy.

Omalizumab is recommended to be administered as a subcutaneous injection. The dose and frequency of dosing are guided by a nomogram that is derived from the total serum IgE level and the body mass index $[6,7]$.

Considering asthma, according to the US FDA, omalizumab is approved in adults and adolescents (12 years of age and above) with moderate to severe persistent asthma who have a positive skin or blood test to a perennial aeroallergen and whose symptoms are inadequately controlled with inhaled corticosteroids (Table 1) [6]. In the EU, according to the European Medicines Agency (EMA), omalizumab is approved as add-on therapy in adults, adolescents, and children ( 6 to $<12$ years of age) with severe persistent allergic asthma, who have a reduced lung function, as well as frequent daytime symptoms or nighttime awakenings, and who have multiple documented severe asthma exacerbations, despite daily high-dose inhaled corticosteroids, plus a long-acting inhaled beta2agonist (Table 1) [7].

In 2012, the UK National Institute for Health and Care Excellence (NICE) published an appraisal on the clinical and cost effectiveness of omalizumab within its licensed indication for the treatment of severe persistent allergic asthma in children aged 6-11 years, after the extension of the treatment to this age group [8]. The analysis concluded that omalizumab appears to reduce clinically significant exacerbations, but there was no evidence of improvement in daily symptoms, clinically significant severe (CSS) exacerbations, or hospitalization rates. The main driver of cost effectiveness was the reduction in asthma-related mortality associated with a reduction in CSS exacerbations. As the number of CSS exacerbations avoided was low, as is asthma-related mortality in children, the potential small gain in quality-adjusted life-years associated with omalizumab was not sufficient to compensate the high treatment cost, even under the most favorable scenario analyses [8]. Subsequent recommendations by NICE were that omalizumab should not be routinely provided for the treatment of severe persistent allergic asthma in children aged 6-11 years [8]. Moreover, omalizumab may be an efficacious alternative to oral corticosteroids in children with more severe asthma, but an oral corticosteroid-sparing trial would need to be conducted to confirm this [8].

Recently, both the FDA and the EMA have approved omalizumab as add-on therapy for the treatment of chronic spontaneous urticaria (CSU) in adults and adolescents (12 years of age and above) with inadequate response to $\mathrm{H}_{1}$ antihistamine treatment (Table 1) [6,7].

Besides these two approved applications, treatment with omalizumab has been explored in other allergic and nonallergic diseases $[9,10]$. It is important to highlight that, since the FDA has approved omalizumab for children aged 12 years and over, the majority of studies investigating possible off-label applications in pediatric populations set the lower age limit for administration of omalizumab at 12 years $[9,10]$. Moreover, to date, new possible applications have been evaluated only in adults [11]. Most of these trials have only reported preliminary results [11]; further confirmations of efficacy in adult patients are awaited in order to consider possible applications in pediatric patients.

At present, 58 clinical trials investigating the use of omalizumab in children are registered on clinicaltrial.gov.

The increasing interest in omalizumab is due to evidence of both efficacy and safety [12]. In particular, in terms of safety, data obtained from patient populations including adults, adolescents, and children within the context of clinical studies and post-marketing surveillance showed that omalizumab was generally well tolerated [12].

Corren et al. [13] analyzed the safety of omalizumab using data from completed clinical studies involving more than 7,500 patients, including adults, adolescents, and children, treated for up to 1 year; in one study, patients with severe allergic asthma were treated for up to 4 years. The analysis has focused on the risk of immune system effects, hypersensitivity reactions, malignant neoplasia, parasitic infections, and thrombocytopenia. Omalizumab showed a good safety and tolerability profile: the incidence of anaphylaxis in the controlled studies (investigator reported) was $0.14 \%$ in omalizumab-treated patients and $0.07 \%$ in control patients [13]. Incorvaia et al. [10] 
Table 1 Licensed therapeutic indication of omalizumab for pediatric age

\begin{tabular}{|c|c|}
\hline US Food and Drug Administration [6] & European Medicines Agency [7] \\
\hline \multicolumn{2}{|l|}{ Pediatric allergic asthma } \\
\hline $\begin{array}{l}\text { Omalizumab is indicated for adolescents (aged } \geq 12 \text { years) with } \\
\text { moderate to severe persistent asthma who have a positive skin test } \\
\text { or in vitro reactivity (blood test) to a perennial aeroallergen and } \\
\text { whose symptoms are inadequately controlled with inhaled } \\
\text { corticosteroids }\end{array}$ & \multirow{2}{*}{$\begin{array}{l}\text { Omalizumab is indicated as add-on therapy to improve asthma control } \\
\text { in adolescents (aged } \geq 12 \text { years) and children (aged } 6 \text { to }<12 \text { years) } \\
\text { with severe persistent allergic asthma who have a positive skin test } \\
\text { or in vitro reactivity (blood test) to a perennial aeroallergen and who } \\
\text { have frequent daytime symptoms or night-time awakenings and who } \\
\text { have had multiple documented severe asthma exacerbations despite } \\
\text { daily high-dose inhaled corticosteroids, plus a long-acting inhaled } \\
\text { beta2-agonist. Patients aged } \geq 12 \text { years must also have reduced lung } \\
\text { function (FEV } \mathrm{FV}_{1}<80 \% \text { of normal) }\end{array}$} \\
\hline $\begin{array}{l}\text { Limitations of use: omalizumab is not indicated for the relief of acute } \\
\text { bronchospasm or status asthmaticus; omalizumab is not indicated for } \\
\text { treatment of other allergic conditions }\end{array}$ & \\
\hline \multicolumn{2}{|l|}{ Chronic spontaneous urticaria } \\
\hline $\begin{array}{l}\text { Omalizumab is indicated for the treatment of adolescents (aged } \\
\geq 12 \text { years) with chronic idiopathic urticaria who remain } \\
\text { symptomatic despite } \mathrm{H}_{1} \text { antihistamine treatment }\end{array}$ & \multirow[t]{2}{*}{$\begin{array}{l}\text { Omalizumab is indicated as add-on therapy for the treatment of } \\
\text { chronic spontaneous urticaria in adolescent (aged } \geq 12 \text { years) } \\
\text { patients with inadequate response to } H_{1} \text { antihistamine treatment }\end{array}$} \\
\hline $\begin{array}{l}\text { Limitation of use: omalizumab is not indicated for the treatment of } \\
\text { other forms of urticaria }\end{array}$ & \\
\hline
\end{tabular}

$F E V_{1}$ forced expiratory volume in $1 \mathrm{~s}$

observed that the anaphylaxis incidence of $0.14 \%$ is similar to the incidence of anaphylactic reactions for other drugs, such as oral penicillin, aspirin, and non-steroidal anti-inflammatory drugs, as well as to the incidence of anaphylaxis reported in the general population.

Post-marketing data, based on an estimated exposure of 57,300 patients between June 2003 and December 2006, showed that the frequency of anaphylaxis attributed to omalizumab use was estimated to be at least $0.2 \%$ of patients [13].

Recently, the Omalizumab Joint Task Force (OJTF) of the American Academy of Allergy, Asthma and Immunology and the American College of Allergy, Asthma and Immunology Executive Committees has recently evaluated the evolution of available data, concluding that post-marketing reports continue to be infrequent $[14,15]$. However, the OJTF established guidelines when treating patients with omalizumab, which include prescribing an epinephrine autoinjector to all patients receiving omalizumab, with training on proper use, and observing all patients for $2 \mathrm{~h}$ after the first three injections and for 30 min after all other injections [14, 15].

The aim of the present review is to assess the application of omalizumab as a therapy in the pediatric population. We identified studies from MEDLINE, the Cochrane Controlled Trials Register (CENTRAL) databases and ClinicalTrials.gov using the keywords 'omalizumab' and 'children'. We also performed a search of relevant files from the FDA (www.fda.gov) and EMA (http://www.ema. europa.eu) databases. References of the retrieved articles were also screened. We set no language restrictions. The approved indications-allergic asthma and CSU—are discussed. Moreover, we analyzed further potential applications of omalizumab in a number of IgE-mediated and non-IgE-mediated diseases.

\section{Licensed Therapeutic Indications}

\subsection{Pediatric Allergic Asthma}

International asthma guidelines [16-18], also supported by the latest international consensus on pediatric asthma [19], currently recommend omalizumab for children with moderate to severe allergic asthma not controlled with other medications, which in many cases will include high-dose inhaled corticosteroids in combination with a long-acting $\beta 2$-agonist.

The licensed therapeutic indications of omalizumab for children and adolescents with allergic asthma are reported in Table 1.

Since the first launch of omalizumab, its earliest efficacy and safety data have been assessed in adults and adolescents ( $\geq 12$ years) but not in younger children because of the lack of appropriately designed pediatric trials [20-24]. Most of the available evidence has been established in well-designed clinical trials conducted mainly in subjects aged between 12 and 75 years: the adolescent group (12-17 years) included in these studies represented only a small percentage of the overall sample (between 6 and $8 \%$ ) [12].

In the last 10 years, compelling evidence from randomized clinical trials and real-world studies conducted in pediatric populations has shown that adding omalizumab to current asthma therapy is effective and well tolerated in children (aged 6-12 years) with uncontrolled allergic asthma [12]. 
In 2001, a double-blind, randomized, and placebo-controlled 28-week trial first evaluated the impact of omalizumab in the treatment of 334 children (aged 6-12 years) with moderate to severe allergic asthma requiring treatment with inhaled corticosteroids [25]. Children were randomized to subcutaneously administered placebo $(N=109)$ or omalizumab $(N=225)$ at a dose based on body weight and initial serum IgE. The efficacy of omalizumab versus placebo was evaluated over three phases: 16 weeks when inhaled steroid (beclomethasone dipropionate [BDP]) therapeutic doses were kept stable (stable-steroid phase), followed by an 8-week steroid-reduction phase to the minimum effective dose, and then maintained constant for the final 4 weeks [25]. The reduction in BDP dose was significantly greater in the omalizumab group than in the placebo group (median reduction 100 vs. $66.7 \%$ ), and a significantly greater percentage of omalizumab-treated patients $(55 \%)$ could reduce their BDP dose to withdrawn completely without losing asthma control. For the omalizumab group, the incidence and frequency of asthma exacerbations achieved a statistically significant reduction during the steroid-reduction phase, during which fewer participants in the omalizumab group had asthma exacerbation episodes (18.2 vs. $38.5 \%$ for placebo; $P<0.001$ ), and the mean number of episodes per patient was smaller than with placebo $(0.42$ vs. $2.72 ; P<0.001)$ [25]. Omalizumab was well tolerated, with no evidence of clinically significant drug toxicity or serious treatment-related adverse events (AEs); the frequency of all AEs was similar in the omalizumab group and the placebo group (89.3 vs. $87.2 \%$ ), and the majority of AEs were mild to moderate in severity [25]. The most commonly reported AEs were headache (36.0 vs. $30.3 \%$ for placebo), pharyngitis $(25.8$ vs. $23.9 \%$ for placebo), upper respiratory tract infection (34.7 vs. $35.8 \%$ for placebo), and viral infection (24.9 vs. $22.9 \%$ for placebo). Urticaria was reported in nine omalizumab patients ( $4 \%$ ) compared with one placebo patient (0.9 \%) [25]. Study-drug-related AEs occurred more frequently in the omalizumab group than in the placebo group (6.2 vs. $0.9 \% ; P=0.029$ ), and they included urticaria $(1.3 \%)$, rash $(0.4 \%)$, flushing $(0.4 \%)$, and pruritus $(0.4 \%)$. Injection site pain or other local skin reactions (burning, itching, warmth, bruising, redness, hive formation, rashes) occurred in $37.5 \%$ of omalizumab-treated and $36.6 \%$ of placebo-treated patients [25].

An analysis on asthma-related quality of life (AQoL) was subsequently carried out in these patients, via administration of the Pediatric Asthma Quality of Life Questionnaire (PAQLQ) at treatment baseline, at the end of the steroid-stable treatment phase, and at the end of the steroidreduction phase [26]. Baseline PAQLQ scores reflected minimal impairment in AQoL in both groups, indicating good control of asthma before starting treatments; therefore, a lack of significant differences between treatments was observed during the steroid-stable phase [26]. However, at the end of the study, changes from baseline in the activities and symptoms domain scores, as well as in overall AQoL, were significantly higher for omalizumab than placebo $(P<0.05)$; likewise, a greater proportion of patients in the omalizumab group achieved a clinically relevant improvement in AQoL (defined as an increase in score of $\geq 0.5$ points from baseline) than in the placebo group, reaching statistical significance only for the activities domain and the overall AQoL score $(P<0.05)$ [26]. When considering a large improvement in AQoL (defined as an increase in score of $\geq 1.5$ points from baseline), the difference between the omalizumab-treated and placebotreated groups was particularly marked for the activities domain (23.3 vs. $14.0 \%$, respectively; $P=0.995)$, symptoms domain (16.0 vs. $9.3 \%$, respectively; $P=0.1814)$, and overall score (13.7 vs. $8.1 \%$, respectively; $P=0.2258$ ) [26].

Surveillance on the long-term safety of omalizumab was studied in an open-label extension of the study by Milgrom et al. [25], in which the active drug was administered to all children for an additional 24 weeks [27]; the reported incidence of AEs in patients treated with omalizumab for the overall 52 weeks was generally comparable to that for placebo [27]. Upper respiratory tract infection and headache were the most frequently reported AEs (47.1 and $42.7 \%$, respectively). Urticaria occurred in 11 of 225 $(4.9 \%)$ patients receiving omalizumab for 52 weeks. Urticaria was mild to moderate in severity, and was suspected to be drug related in five patients; it resolved spontaneously or with antihistamine, except for one patient who was discontinued because of generalized urticaria [27]. No AEs suggestive of serum sickness or immune complex formation occurred; no anti-omalizumab antibodies were detected in any of the children [27].

In 2009, Lanier et al. [28] conducted a randomized, double-blind, placebo-controlled, parallel-group trial in 627 children (aged 6 to $<12$ years) with moderate-tosevere persistent allergic asthma inadequately controlled despite medium to high doses of inhaled corticosteroids. Children were randomized to subcutaneously administered placebo $(N=206)$ or omalizumab $(N=421)$ at a dose based on body weight and initial serum IgE. Over a period of 52 weeks (24-week fixed-steroid phase followed by a 28-week adjustable-steroid phase), omalizumab was effective, significantly reducing the rate of clinically significant asthma exacerbations by $43 \%$ versus placebo ( 0.78 vs. $1.36 ; P<0.001)$, with an acceptable safety profile [28]. The overall incidence of AEs was similar in the omalizumab and placebo groups (90.3 vs. $93.7 \%$ ), and most AEs were mild or moderate in severity. Moreover, the overall incidence of serious AEs (SAEs) was lower in the 
omalizumab group than in the placebo group (4 vs. $8 \%$; $P<0.05)$ [28]

In a further randomized, double-blind, placebo-controlled study by Kulus et al. [29], add-on treatment with omalizumab reduced the rate of clinically significant asthma exacerbations by $34 \%$ versus placebo $(0.42$ vs. $0.63 ; P=0.047)$ over a first 24 -week fixed-steroid dosing period in 235 children aged 6 to $<12$ years (omalizumab, $N=159$; placebo, $N=76$ ) with severe allergic asthma inadequately controlled despite combination therapy. Extending the treatment period to 52 weeks (24-week fixed-steroid plus 28 -week adjustable-steroid phases), the exacerbation rate was reduced by $50 \%$ (0.73 in omalizumab-treatment patients vs. 1.44 in placebo-treated patients; $P<0.001$ ).

In 2011, Busse et al. [30] published the results of the ICATA (inner city anti-IgE therapy for asthma) study, a randomized, double-blind, placebo-controlled, parallelgroup, multicenter trial of omalizumab in 419 inner-city children, adolescents, and young adults (6-20 years of age) with persistent allergic asthma; children were randomized to subcutaneous placebo $(N=211)$ or omalizumab $(N=208)$ at a dose based on body weight and initial serum IgE. Omalizumab as compared with placebo significantly reduced the number of days with asthma symptoms from 1.96 to 1.48 days per 2-week interval, a $24.5 \%$ decrease $(P<0.001)$. Similarly, it significantly reduced the proportion of participants who had one or more exacerbations from 48.8 to $30.3 \%(P<0.001)$ [30]. Moreover, the authors identified a specific subgroup of potential responders to omalizumab in patients who were sensitized to cockroach antigens; compared with patients who were neither sensitized nor exposed to cockroach allergen, those receiving omalizumab had bigger reductions in inhaled corticosteroid dose $(P=0.03)$ and asthma exacerbations $(P=0.06)$ and increased odds of not having an asthma exacerbation $(P=0.06)$ [30]. The authors also demonstrated the effects of omalizumab on seasonal patterns of both symptoms and exacerbations; in fact, the average monthly rate of asthma exacerbations nearly doubled in the placebo group during fall and spring as compared with summer $(9.0$ and $8.1 \%$ vs. $4.6 \%$, respectively; $P<0.001)$. This seasonal spike in exacerbations was not observed in the omalizumab group (4.3\% in fall, $4.2 \%$ in spring, $3.3 \%$ in summer), and the difference between the placebo and omalizumab groups was significant $(P<0.001$ for interaction) [30].

Regarding safety, Milgrom et al. [31] presented a pooled safety analysis of two double-blind, placebo-controlled studies in children (aged 6 to $<12$ years) with moderate-tosevere allergic asthma, investigating both the efficacy and the safety of omalizumab. Of 926 children (omalizumab, $N=624$; placebo, $N=302$ ), the most common AEs were nasopharyngitis, upper respiratory tract infection, and headache, and they were more frequently reported in the placebo $(91.7 \%)$ than in the omalizumab group $(89.7 \%)$ group. Suspected treatment-related AEs included headache, erythema, and urticaria, none of which were reported by $\geq 2 \%$ of patients receiving omalizumab. SAEs were reported by 3.4 and $6.6 \%$ of patients receiving omalizumab and placebo, respectively; the most common were appendicitis, pneumonia, and bronchitis. No deaths were reported [31].

Furthermore, a systematic review by Rodrigo et al. [32] supported the indication given in international guidelines for the use of subcutaneous omalizumab as add-on therapy to corticosteroids in children with moderate to severe persistent allergic asthma, first taking into account the latest randomized placebo-controlled trials performed in a pediatric population.

The evidence for a steroid-sparing impact of omalizumab treatment was reported by Brodlie et al. [33] in a small, uncontrolled study of children and adolescents (aged 5-16 years) with severe allergic asthma in the UK. After a 16-week therapeutic trial in 34 patients, the omalizumab add-on treatment allowed a significant reduction in daily prednisolone dose from $20 \mathrm{mg}$ at baseline to $5 \mathrm{mg}$ $(N=34, P<0.0001)$, and improved asthma control and quality of life (childhood asthma control test [ACT] score increased from 12 to 20 points; $N=23, P=0.0001$ ) in more than $90 \%$ of children. These uncontrolled data, while very encouraging, were obtained in a relatively small patient cohort and should be interpreted with appropriate caution [33].

In 2013, Deschildre et al. [34] conducted the first pediatric real-world study with the aim of extending previous omalizumab efficacy and safety observed in randomized trials and, moreover, to assess its effect on disease control as an efficacy outcome. This 1-year observational study was conducted in a large group of children and adolescents ( $N=104$, aged $<18$ years) with severe allergic asthma in France. Omalizumab was administered as required by the dosing table, according to IgE levels and weight [34]. The results of this study went beyond those of previously reported clinical trials: asthma control, defined according to Global Initiative for Asthma (GINA) criteria, improved significantly over 52 weeks (asthma control was 'good' for $0 \%$ of the population at treatment initiation and improved to $67 \%$ of patients; $P<0.0001$ ). The other main finding was a $72 \%$ reduction in the rate of severe exacerbations (the mean rate of severe exacerbations decreased from 4.4 per patient during the previous year to 1.25 during the year of treatment; $P<0.0001$ ), as well as a $30 \%$ reduction in the inhaled corticosteroid dose $(P<0.0001)$; moreover, the percentage of children requiring hospitalization decreased from $44 \%$ in the past year to $6.7 \%$ 
$(P<0.001)$ [34]. Furthermore, omalizumab was also generally well tolerated in the real-world setting, with the most frequent AEs consisting of pain and local reaction at injection site $(N=33)$ [34]; however, the author also reported SAEs such as one case of extended urticaria, one case of anaphylaxis that was unrelated to omalizumab but linked to fruit allergy, and four cases of systemic reactions associated with abdominal and muscular pain, fatigue, and headache [34].

Although these data are the result of an observational study, they do reflect the previous findings of randomized controlled trials, indicating that they should be generalizable to clinical practice [34].

Finally, in 2014, a systematic Cochrane review analyzed the efficacy of omalizumab in more than 25 randomized, placebo-controlled clinical trials involving adults, adolescents, and children with moderate to severe asthma; three of these studies focused exclusively on a pediatric or adolescent population, and, in adult studies, the adolescent population was represented by a small percentage (6-8\%) [12]. For this reason, the authors required a further clinical assessment in the pediatric population. However, based on all the studies considered, they concluded that omalizumab was effective in reducing asthma exacerbations and hospitalizations as an adjunctive therapy to inhaled steroids and during steroidtapering phases of clinical trials. Furthermore, omalizumab was generally well tolerated, with the only exception being transient injection site reactions [12].

Omalizumab has proven to be safe and beneficial in children with allergic asthma in trials of 1-year duration $[12,28,31]$; its long-term safety and efficacy have been evaluated in adults [35] but not yet demonstrated in a pediatric population.

To date, strong biological markers to identify responders are still lacking. These issues, as well as further cost-utility analyses, are still open and need to be investigated in future pediatric studies.

\subsection{Chronic Spontaneous Urticaria}

Urticaria is a disease characterized by the development of wheals (hives), angioedema, or both [36]. Urticaria needs to be differentiated from other medical conditions where wheals, angioedema, or both can occur as a symptom (for example, the skin prick test, anaphylaxis, auto-inflammatory syndromes, or hereditary angioedema [bradykininmediated angioedema]) [36].

CSU is a chronic urticarial subtype, defined as itchy hives that last for at least 6 weeks, with or without angioedema, and that have no apparent external trigger [36]. It is estimated that $0.5-1 \%$ of the population experiences this condition, which generally has a prolonged duration and has a detrimental effect on patients' quality of life [37, 38].
The pathogenesis of CSU is uncertain but has been associated with histamine release from cutaneous mast cells and blood basophils [39]. Furthermore, it has been recently hypothesized that autoreactivity may play a larger role in CSU than previously thought [39]; about one-third of patients with CSU test positive in the autologous serum skin test, indicating the presence of autoantibodies or histamine-releasing factors, and approximately one-third produce $\operatorname{IgG}$ autoantibodies against $\operatorname{IgE}$ or FceRI, and cross-linking of autoantibodies bound to FceRI leads to degranulation of mast cells and basophils and the release of histamine [39].

Before the FDA and EMA approval of omalizumab, non-sedating $\mathrm{H}_{1}$-antihistamines were the only agents licensed for use in patients with CSU. However, a majority of patients did not respond to these drugs, even when they were administered at three to four times their licensed dose [40].

Recently, the FDA and the EMA approved omalizumab for the treatment of CSU in adults and children 12 years and above with inadequate response to $\mathrm{H}_{1}$-antihistamines $[6,7]$.

To date, the potential pharmacologic mechanism of omalizumab in CSU has not been determined; it has been hypothesized that the depletion of free IgE by omalizumab, with subsequent downregulation of FceRI and FceRII, as well as possible sequestration of incoming allergen molecules by omalizumab-IgE immune complexes, may abolish the ability of IgE to potentiate mast cell activity in this way [39].

Interestingly, the mechanism of omalizumab appears to be different in urticaria and allergic asthma, for which the drug has been licensed previously. In urticaria, dosage is not dependent on serum IgE levels, and response is seen very often after only $12 \mathrm{~h}$ [39].

The approval of omalizumab for the treatment of CSU is primarily based on the results from three pivotal phase III clinical trials known as ASTERIA I, ASTERIA II, and GLACIAL [41-43].

The ASTERIA II study (Clinicaltrials.gov identifier: NCT01292473) evaluated the efficacy and safety of omalizumab in 323 patients (adults and adolescents $\geq 12$ years) with moderate to severe CSU not responding to antihistamine therapy. Only $3 \%$ of these patients were aged between 12 and 17 years [42]. Patients were randomized to omalizumab $75 \mathrm{mg}, 150 \mathrm{mg}$, or $300 \mathrm{mg}$ or placebo, administered subcutaneously every 4 weeks, for a total of three doses within a 12-week treatment period, followed by a 16-week follow-up period. At week 12, the mean ( \pm standard deviation [SD]) change from baseline in weekly itch severity score was $-5.1 \pm 5.6$ in the placebo group, $-5.9 \pm 6.5$ in the $75 \mathrm{mg}$ group $(P=0.46),-8.1 \pm 6.4 \mathrm{in}$ the $150 \mathrm{mg}$ group $(P=0.001)$, and $-9.8 \pm 6.0$ in the 
$300 \mathrm{mg}$ group $(P<0.001)$ [42]. The rate of AEs was low and similar across the groups, although it was higher in the 300-mg group (6\%) than in the placebo group (3\%) or in either the $75-$ or the $150-\mathrm{mg}$ group ( $1 \%$ for each) [42].

In the GLACIAL study (Clinicaltrials.gov identifier NCT01264939), 336 patients (adults and adolescents $\geq 12$ years) - with persistent CSU despite treatment with $\mathrm{H}_{1}$-antihistamines at up to 4 times the approved dose plus $\mathrm{H}_{2}$-antihistamines, leukotriene receptor antagonists, or both-were randomized to receive six subcutaneous injections at 4-week intervals of either omalizumab $300 \mathrm{mg}$ or placebo, followed by a 16-week observation period [43]. The primary objective was to evaluate the safety of omalizumab compared with placebo. The overall incidence and severity of AEs was similar between omalizumab and placebo recipients [43]. Efficacy was evaluated at weeks 12 and 24 and included itch severity, wheal, and urticaria activity scores. At week 12, the mean change from baseline in weekly itch severity score was -8.6 (95\% confidence interval $[\mathrm{CI}]-9.3$ to -7.8$)$ in the omalizumab group compared with $-4.0(95 \% \mathrm{CI}-5.3$ to -2.7$)$ in the placebo group $(P<0.001)$. These benefits were sustained to week 24 [43]. However, it is not clear how many adolescent patients were involved in this study.

Recently, the results from a third clinical trial with omalizumab in CSU were presented [41]. In the ASTERIA I study (ClinicalTrials.gov identifier NCT01287117), patients aged 12-75 years with CSU who remained symptomatic despite $\mathrm{H}_{1}$-antihistamine treatment were randomized to receive omalizumab 75,150 , or $300 \mathrm{mg}$ or placebo every 4 weeks during the 24-week treatment period [41]. Only $6 \%$ of these patients were aged between 12 and 17 years [41, 44]. Efficacy results in ASTERIA I were consistent with those from ASTERIA II and GLACIAL [44]. All these findings show that omalizumab reduces clinical symptoms and signs of CSU resistant to antihistamines [41-44]. These results had a strong influence on clinical practice.

The recently updated guideline for the definition, classification, diagnosis, and management of urticaria recommend a trial of omalizumab as add-on therapy to modern second-generation $\mathrm{H}_{1}$-antihistamines as third line in the algorithm of treatment of urticaria (strong recommendation/high level of evidence) [36].

Unfortunately, there is little published information about CSU in children [45]. Consequently, most of the recommendations contained in current guidelines for the prevention and treatment of CSU in children is based on extrapolation of data obtained in adults and adolescents [45]. To date, omalizumab has not been studied in children with CSU aged $<12$ years [46].

\section{Further Potential Clinical Applications: Off-Label Indications}

In recent years, several studies have investigated the possible applications of omalizumab in a number of IgEmediated and non-IgE-mediated diseases $[9,10]$.

\subsection{Allergic Rhinitis}

Omalizumab has been reported to be effective for the treatment of patients with seasonal allergic rhinitis (SAR) and persistent allergic rhinitis (PAR) [47-51]. Results from clinical trials demonstrated that omalizumab improved symptoms, quality of life, and necessity of rescue medications in adults and adolescents ( $>12$ years and above) with allergic rhinitis (AR) [47-51].

In a meta-analysis of randomized clinical trials, Tsabouri et al. [52] assessed the efficacy and safety of omalizumab in patients with poorly controlled AR. Of 11 clinical trials included in the meta-analysis, two studies referred to the same clinical trial with a sample size of 221 patients and included only children and adolescents aged 6-17 years (mean age 12 years) and another four trials included pediatric patients. Of these, two reported the proportion of the included pediatric patients (9 and $23 \%$, respectively), whereas the other two did not provide further information [52]. The clinical trial conducted specifically in children was in combination with subcutaneous immunotherapy (SCIT) and is also discussed separately below [58]. Overall, a statistically significant reduction in the daily nasal symptom severity score and in daily nasal rescue medication score was observed [52]. According to this evidence, omalizumab may provide a new treatment strategy for AR. In particular, omalizumab may benefit patients with moderate-severe AR with proven allergenspecific antibodies who have no sufficient response to recommended medications [52]. Moreover, treatment with omalizumab would be beneficial in patients with comorbid AR and asthma [53]. The recently published position paper on pediatric rhinitis by the European Academy for Allergy and Clinical Immunology (EAACI) considers omalizumab as a possible treatment for patients with AR and moderateto-severe asthma when other recommended therapies are ineffective [54]. However, the use of omalizumab for the treatment of AR has not been approved, and the high cost limits this application. Nevertheless, its periodic off-label use may be justified in patients with severe disease not responding to standard treatments [55].

Recently, the use of anti-IgE antibody therapy in addition to conventional SCIT has been explored in several trials [56-59]. In particular, the combination of omalizumab with SCIT in patients with SAR and comorbid seasonal allergic asthma has been proved to be safe and 
efficient in reducing the symptom load during the pollen season in a patient population that included approximately $25 \%$ adolescents ( $>12$ years and above) $[56,57]$.

Considering the pediatric population, a randomized, double-blind, placebo-controlled trial involving 221 children (aged 6-17 years) with SAR was conducted with the aim of exploring the additional anti-allergic effect of omalizumab in combination with SCIT [58]. The combination therapy with SCIT and omalizumab resulted in a significant reduction in rescue medication use $(86 \%$, $P=0.001)$ and number of symptomatic days (61\%, $P \leq 0.001)$; moreover, this combined treatment showed superior efficacy on symptom severity compared with SCIT alone (nasal symptoms: median 0.45 vs. 0.32 , $P=0.025$ ) [58]. Furthermore, a safety analysis on the same population showed a good tolerability of SCIT + omalizumab (82\% of patients); the AEs with possible causal relationship to treatment occurred slightly more often in the groups treated with omalizumab (24.8 vs. $16.0 \%$ for placebo), particularly local reactions (16.8 vs. $12.3 \%)$ and some systemic, gastrointestinal (2.7 vs. $0.9 \%$ ) and ear symptoms (1.8 vs. $0 \%$ ) [59]. Most AEs (93.4\% with omalizumab and $87.2 \%$ with placebo) were judged by the patients as mild to moderate. Finally, redness and swelling at the SCIT injection site appeared significantly more often in the placebo group (52 vs. $37 \%, P=0.01$; 38 vs. $17 \%, P=0.001$, respectively), which suggests a positive effect of omalizumab on local reaction induced by SCIT [59]. These results potentially disclose new perspectives for the application of SCIT in the pediatric population; however, there are no data available as to whether this combination therapy is also cost effective.

\subsection{Allergic Bronchopulmonary Aspergillosis}

Allergic bronchopulmonary aspergillosis (ABPA) is a lung disease caused by aspergillus-induced hypersensitivity. This condition is more frequent in patients with cystic fibrosis, with a prevalence of 2-15\% [60]. Systemic corticosteroids remain the mainstay of treatment, and antifungal agents are added to reduce the aspergillus antigen burden. However, corticosteroid adverse effects have led to the exploration of novel therapeutic interventions [60].

Since elevated total $\mathrm{IgE}$ is a cardinal abnormality of ABPA, omalizumab has been used sporadically in an effort to decrease corticosteroid dose or totally replace corticosteroids [61].

A review of current evidence on the use of omalizumab for ABPA in children with cystic fibrosis showed that there is a limited published literature and all available data are obtained from case reports [61]. In the eight case reports analyzed, treatment with omalizumab was associated with improved expiratory flow function, reduced frequency of respiratory symptoms, and decreased use of systemically administered corticosteroids [61]. There are no randomized, placebo-controlled trials evaluating this treatment approach in the pediatric population.

As assessed by the Cochrane Collaboration, there is a need for large prospective randomized controlled trials of anti-IgE therapy in people with cystic fibrosis and ABPA, with both clinical and laboratory outcome measures such as steroid requirement, ABPA exacerbations, and lung function [62].

\subsection{Nasal Polyposis}

The clinical efficacy and safety of omalizumab has been recently evaluated in a randomized, double-blind, placebocontrolled trial, including a small population of adults with chronic rhinosinusitis with nasal polyposis and comorbid asthma [63]. Further studies in adult patients are awaited in order to consider the possible application of anti-IgE therapy in children.

\subsection{Severe Refractory Atopic Dermatitis}

Severe refractory atopic dermatitis (AD) is a chronic debilitating condition that is associated with elevated serum IgE levels [64].

Small reports and a pilot study in adults and adolescents investigating anti-IgE therapy in patients with severe refractory $\mathrm{AD}$ found symptomatic improvement with omalizumab [65-69].

No literature are available for the pediatric population; Lacombe Barrios et al. [70] only reported a small case series of five children and two adolescents with severe AD treated with omalizumab in a study strongly limited by the absence of a placebo control group. Thus, further studies are needed to evaluate the role and efficacy of anti-IgE therapy in patients with severe AD.

\subsection{Food Allergy and Anaphylaxis}

Food allergy is defined as an adverse reaction to a food allergen caused by immunologic mechanisms; the IgEmediated form occurs with different degrees of severity, ranging from mild oral allergy syndrome to anaphylaxis [71].

Anaphylaxis is a severe, potentially life-threatening systemic hypersensitivity reaction, characterized by being rapid in onset, with life-threatening airway, breathing, or circulatory problems and is usually, although not always, associated with skin and mucosal changes [72]. It can involve allergic and non-allergic mechanisms; most cases of anaphylaxis involve an IgE-mediated mechanism, such as that seen in food-induced anaphylaxis [72]. 
Considering its efficacy in reducing serum IgE levels and downregulating the cell surface expression of FceRI, omalizumab has been explored for other IgE-associated conditions, such as IgE-mediated food allergy and foodinduced anaphylaxis [73].

The first randomized, double-blind, placebo-controlled, clinical trial investigating the effect of anti-IgE therapy in food allergy was conducted in 84 patients (aged 12-60 years) with peanut allergy, including only 18 patients aged 12-17 years. Patients were randomized to receive monthly subcutaneous injections of one of three doses of another anti-IgE molecule known as TNX-901 $(150,300$, or $450 \mathrm{mg})$ or placebo for a total of 4 months [74]. Within 2-4 weeks of the last dose, patients were challenged with increasing amounts of peanuts until a clinical reaction occurred [74]. Treatment with TNX-901, rather than omalizumab, increased the threshold dose of peanut eliciting a clinical reaction in a dose-dependent manner, and this was statistically significant only at the highest dose $(450 \mathrm{mg}$ ) when compared with placebo [74].

Subsequent studies examined the use of omalizumab as a therapy for food allergy. Sampson et al. [75] recently started a phase II clinical trial with omalizumab. This was a multicenter, randomized, double-blind, placebo-controlled trial designed to enroll 150 peanut allergic subjects (aged 6-75 years); however, due to the severe reactions (anaphylaxis) that occurred during the peanut challenge performed prior to receiving any drug, the study was terminated early. As a result, only 14 subjects, including seven pediatric patients, completed the study [75].

Recently, the role of omalizumab in reducing allergic reactions to food allergen challenges was investigated in patients undergoing food immunotherapy. A small pilot open-label study evaluated the use of omalizumab as an adjuvant to milk oral immunotherapy in 11 pediatric patients (aged 7-17 years). Pre-treatment with omalizumab for 7-11 weeks enabled nine children to tolerate the rush desensitization milk protocol (from 0.1 to $1,000 \mathrm{mg}$ of milk protein over 1 day) [76].

Currently, there are no data to support the role of omalizumab as monotherapy in the induction of tolerance in food-allergic patients. To date, several clinical trials (clinicaltrials.gov identifiers NCT02062814, NCT01157117, NCT01290913, NCT00932282), all involving children as well as adults, are examining the use of omalizumab in desensitization protocols to various foods, particularly milk and peanut [73].

\subsection{Other Disorders}

Although anecdotal evidence of utility has been reported, no formal trials are examining the off-label use of omalizumab in other pediatric disorders, such as mast cell diseases (systemic mastocytosis or mast cell activation syndrome), exercise-induced anaphylaxis, eosinophilic gastrointestinal diseases, severe vernal keratoconjunctivitis, or skin bullous disorders $[9,10]$.

\section{Conclusion}

Although its use has been approved only in moderate-tosevere uncontrolled allergic asthma and in CSU, omalizumab has been explored in several pediatric conditions. Further studies including clinical efficacy, safety, and costbenefit ratios as primary outcomes are needed to translate these findings into clinical practice, especially in the pediatric population.

Acknowledgments A. Licari, A. Marseglia, S. Caimmi, R. Castagnoli, T. Foiadelli, S. Barberi and G.L. Marseglia have no relevant affiliations or financial involvement with any organization or entity with a financial interest in or financial conflict with the subject matter or materials discussed in this review. No funding has been received for the drafting of this manuscript.

Open Access This article is distributed under the terms of the Creative Commons Attribution Noncommercial License which permits any noncommercial use, distribution, and reproduction in any medium, provided the original author(s) and the source are credited.

\section{References}

1. Holgate S, Casale T, Wenzel S, Bousquet J, Deniz Y, Reisner C. The anti-inflammatory effects of omalizumab confirm the central role of $\mathrm{IgE}$ in allergic inflammation. $\mathrm{J}$ Allergy Clin Immunol. 2005;115:459-65.

2. Gould HJ, Sutton BJ. IgE in allergy and asthma today. Nat Rev Immunol. 2008;8(3):205-17.

3. Prussin C, Griffith DT, Boesel KM, Lin H, Foster B, Casale TB. Omalizumab treatment downregulates dendritic cell FcepsilonRI expression. J Allergy Clin Immunol. 2003;112(6):1147-54.

4. Holgate S, Smith N, Massanari M, Jimenez P. Effects of omalizumab on markers of inflammation in patients with allergic asthma. Allergy. 2009;64(12):1728-36.

5. Djukanović R, Wilson SJ, Kraft M, Jarjour NN, Steel M, Chung $\mathrm{KF}$, et al. Effects of treatment with anti-immunoglobulin $\mathrm{E}$ antibody omalizumab on airway inflammation in allergic asthma. Am J Respir Crit Care Med. 2004;170(6):583-93.

6. Food and Drug Administration. http://www.accessdata.fda.gov/ drugsatfda_docs/label/2014/103976s5211lbl.pdf.

7. European Medicines Agency. http://www.ema.europa.eu/ema/ index.jsp?curl=pages/medicines(human/medicines/000606/human med_001162.jsp\&mid=WC0b01ac058001d124.

8. Burch J, Griffin S, McKenna C, Walker S, Paton J, Wright K, Woolacott N. Omalizumab for the treatment of severe persistent allergic asthma in children aged 6-11 years: a NICE single technology appraisal. Pharmacoeconomics. 2012;30(11): 991-1004.

9. Baena-Cagnani CE, Gómez RM. Current status of therapy with omalizumab in children. Curr Opin Allergy Clin Immunol. 2014;14(2):149-54. 
10. Incorvaia $\mathrm{C}$, Mauro M, Russello M, Formigoni C, Riario-Sforza GG, Ridolo E. Omalizumab, an anti immunoglobulin E antibody: state of the art. Drug Des Devel Ther. 2014;7(8):197-207.

11. Babu KS, Polosa R, Morjaria JB. Anti-IgE-emerging opportunities for Omalizumab. Expert Opin Biol Ther. 2013;13(5):765-77.

12. Normansell R, Walker S, Milan SJ, Walters EH, Nair P. Omalizumab for asthma in adults and children. Cochrane Database Syst Rev. 2014;1:CD003559.

13. Corren J, Casale TB, Lanier B, Buhl R, Holgate S, Jimenez P. Safety and tolerability of omalizumab. Clin Exp Allergy. 2009;39(6):788-97.

14. Cox L, Platts-Mills TA, Finegold I, Schwartz LB, Simons FE, Wallace DV, American Academy of Allergy, Asthma \& Immunology; American College of Allergy, Asthma and Immunology. American Academy of Allergy, Asthma \& Immunology/American College of Allergy, Asthma and Immunology Joint Task Force Report on omalizumab-associated anaphylaxis. J Allergy Clin Immunol. 2007;120(6):1373-7.

15. Cox L, Lieberman P, Wallace D, Simons FE, Finegold I, PlattsMills T, Schwartz L. American Academy of Allergy, Asthma \& Immunology/American College of Allergy, Asthma \& Immunology Omalizumab-Associated Anaphylaxis Joint Task Force follow-up report. J Allergy Clin Immunol. 2011;128(1):210-2.

16. From the Global Strategy for Asthma Management and Prevention, Global Initiative for Asthma (GINA) 2014. Available from: http://www.ginasthma.org/local/uploads/files/GINA_Report_ 2014_Jun11.pdf.

17. Expert Panel Report 3 (EPR3): guidelines for the diagnosis and management of asthma. Bethesda, MD: National Institutes of Health, National Heart, Lung, and Blood Institute, 2007 (http:// www.nhlbi.nih.gov/guidelines/asthma/asthgdln.htm).

18. Omalizumab for treating severe persistent allergic asthma (review of technology appraisal guidance 133 and 201). NICE National Institute for Health and Care Excellence http://www. nice.org.uk/Guidance/TA278.

19. Papadopoulos NG, Arakawa H, Carlsen KH, Custovic A, Gern J, Lemanske R, et al. International consensus on (ICON) pediatric asthma. Allergy. 2012;67:976-97.

20. Hanania NA, Alpan O, Hamilos DL, Condemi JJ, Reyes-Rivera I, $\mathrm{Zhu} \mathrm{J}$, et al. Omalizumab in severe allergic asthma inadequately controlled with standard therapy: a randomized trial. Ann Intern Med. 2011;154(9):573-82.

21. Busse W, Corren J, Lanier BQ, McAlary M, Fowler-Taylor A, Cioppa GD, et al. Omalizumab, anti-IgE recombinant humanized monoclonal antibody, for the treatment of severe allergic asthma. J Allergy Clin Immunol. 2001;108(2):184-90.

22. Humbert M, Beasley R, Ayres J, Slavin R, Hébert J, Bousquet J, et al. Benefits of omalizumab as add-on therapy in patients with severe persistent asthma who are inadequately controlled despite best available therapy (GINA 2002 step 4 treatment): INNOVATE. Allergy. 2005;60(3):309-16.

23. Bousquet J, Siergiejko Z, Swiebocka E, Humbert M, Rabe KF, Smith N, et al. Persistency of response to omalizumab therapy in severe allergic (IgE-mediated) asthma. Allergy. 2011;66(5):671-8.

24. Holgate ST, Chuchalin AG, Hebert J, Lötvall J, Persson GB, Chung KF, et al. Efficacy and safety of a recombinant antiimmunoglobulin $\mathrm{E}$ antibody (omalizumab) in severe allergic asthma. Clin Exp Allergy. 2004;34(4):632-8.

25. Milgrom H, Berger W, Nayak A, Gupta N, Pollard S, McAlary $\mathrm{M}$, et al. Treatment of childhood asthma with anti-immunoglobulin E antibody (omalizumab). Pediatrics. 2001;108(2):E36.

26. Lemanske RF Jr, Nayak A, McAlary M, Everhard F, FowlerTaylor A, Gupta N. Omalizumab improves asthma-related quality of life in children with allergic asthma. Pediatrics. 2002;110(5):e55.
27. Berger W, Gupta N, McAlary M, Fowler-Taylor A. Evaluation of long-term safety of the anti-IgE antibody, omalizumab, in children with allergic asthma. Ann Allergy Asthma Immunol. 2003;91(2):182-8.

28. Lanier B, Bridges T, Kulus M, Taylor AF, Berhane I, Vidaurre $\mathrm{CF}$. Omalizumab for the treatment of exacerbations in children with inadequately controlled allergic (IgE-mediated) asthma. J Allergy Clin Immunol. 2009;124(6):1210-6.

29. Kulus M, Hébert J, Garcia E, Fowler Taylor A, Fernandez Vidaurre $\mathrm{C}$, Blogg $\mathrm{M}$. Omalizumab in children with inadequately controlled severe allergic (IgE-mediated) asthma. Curr Med Res Opin. 2010;26(6):1285-93.

30. Busse WW, Morgan WJ, Gergen PJ, Mitchell HE, Gern JE, Liu $\mathrm{AH}$, et al. Randomized trial of omalizumab (anti-IgE) for asthma in inner-city children. N Engl J Med. 2011;364:1005-15.

31. Milgrom H, Fowler-Taylor A, Vidaurre CF, Jayawardene S. Safety and tolerability of omalizumab in children with allergic (IgE-mediated) asthma. Curr Med Res Opin. 2011;27(1):163-9.

32. Rodrigo GJ, Neffen H, Castro-Rodriguez JA. Efficacy and safety of subcutaneous omalizumab vs placebo as add-on therapy to corticosteroids for children and adults with asthma: a systematic review. Chest. 2011;139(1):28-35.

33. Brodlie M, McKean MC, Moss S, Spencer DA. The oral corticosteroid-sparing effect of omalizumab in children with severe asthma. Arch Dis Child. 2012;97(7):604-9.

34. Deschildre A, Marguet C, Salleron J, Pin I, Rittié JL, Derelle J, et al. Add-on omalizumab in children with severe allergic asthma: a 1-year real life survey. Eur Respir J. 2013;42(5):1224-33.

35. Braunstahl GJ, Chen CW, Maykut R, Georgiou P, Peachey G, Bruce J. The eXpeRience registry: the 'real-world' effectiveness of omalizumab in allergic asthma. Respir Med. 2013;107(8):1141-51.

36. Zuberbier T, Aberer W, Asero R, Bindslev-Jensen C, Brzoza Z, Canonica GW, et al. The EAACI/GAL ${ }^{2} \mathrm{EN} / \mathrm{EDF} / \mathrm{WAO}$ Guideline for the definition, classification, diagnosis, and management of urticaria: the 2013 revision and update. Allergy. 2014;69(7):868-87.

37. Maurer M, Weller K, Bindslev-Jensen C, Giménez-Arnau A, Bousquet PJ, Bousquet $\mathrm{J}$, et al. Unmet clinical needs in chronic spontaneous urticaria. A GA $^{2} \mathrm{LEN}$ task force report. Allergy. 2011;66(3):317-30.

38. Kulthanan K, Jiamton S, Thumpimukvatana N, Pinkaew S. Chronic idiopathic urticaria: prevalence and clinical course. J Dermatol. 2007;34:294-301.

39. Chang TW, Chen C, Lin CJ, Metz M, Church MK, Maurer M. The potential pharmacologic mechanisms of omalizumab in patients with chronic spontaneous urticaria. J Allergy Clin Immunol. 2014. pii: S0091-6749(14)00657-5.

40. Sánchez-Borges M, Asero R, Ansotegui IJ, Baiardini I, Bernstein JA, Canonica GW, WAO Scientific and Clinical Issues Council, et al. Diagnosis and treatment of urticaria and angioedema: a worldwide perspective. World Allergy Organ J. 2012;5(11):125-47.

41. Bernstein JA, Sarbjit SS, Maurer R, Hsin-JU H, Chen H, Canvin $\mathrm{J}$, et al. Efficacy of omalizumab in patients with chronic idiopathic/spontaneous urticaria with different background therapy: post hoc analysis of Asteria I, Asteria II, and Glacial studies. J Allergy Clin Immunol. 2014;133(2 Suppl):AB117.

42. Maurer M, Rosén K, Hsieh HJ, Saini S, Grattan C, GimenézArnau A, et al. Omalizumab for the treatment of chronic idiopathic or spontaneous urticaria. $\mathrm{N}$ Engl $\mathrm{J}$ Med. 2013;368(10):924-35.

43. Kaplan A, Ledford D, Ashby M, Canvin J, Zazzali JL, Conner E, et al. Omalizumab in patients with symptomatic chronic idiopathic/spontaneous urticaria despite standard combination therapy. J Allergy Clin Immunol. 2013;132(1):101-9.

44. Saini SS, Bindslev-Jensen C, Maurer M, Grob JJ, Bülbül Baskan E, Bradley MS, Canvin J, Rahmaoui A, Georgiou P, Alpan O, 
Spector S, Rosén K. Efficacy and safety of omalizumab in patients with chronic idiopathic/spontaneous urticaria who remain symptomatic on $\mathrm{H}_{1}$ antihistamines: a randomized, placebo-controlled study. J Invest Dermatol. Epub 2014 Jul 21.

45. Church MK, Weller K, Stock P, Maurer M. Chronic spontaneous urticaria in children: itching for insight. Pediatr Allergy Immunol. 2011;22(1 Pt 1):1-8.

46. McCormack PL. Omalizumab: a review of its use in patients with chronic spontaneous urticaria. Drugs. 2014;74(14):1693-9.

47. Casale TB, Condemi J, LaForce C, Nayak A, Rowe M, Watrous M, Omalizumab Seasonal Allergic Rhinitis Trial Group, et al. Effect of omalizumab on symptoms of seasonal allergic rhinitis: a randomized controlled trial. JAMA. 2001;286(23):2956-67.

48. Adelroth E, Rak S, Haahtela T, Aasand G, Rosenhall L, Zetterstrom $\mathrm{O}$, et al. Recombinant humanized mAb-E25, an anti-IgE $\mathrm{mAb}$, in birch pollen-induced seasonal allergic rhinitis. J Allergy Clin Immunol. 2000;106(2):253-9.

49. Chervinsky P, Casale T, Townley R, Tripathy I, Hedgecock S, Fowler-Taylor A, et al. Omalizumab, an anti-IgE antibody, in the treatment of adults and adolescents with perennial allergic rhinitis. Ann Allergy Asthma Immunol. 2003;91(2):160-7.

50. Vignola AM, Humbert M, Bousquet J, Boulet LP, Hedgecock S, Blogg M, et al. Efficacy and tolerability of anti-immunoglobulin E therapy with omalizumab in patients with concomitant allergic asthma and persistent allergic rhinitis: SOLAR. Allergy. 2004;59(7):709-17.

51. Nayak A, Casale T, Miller SD, Condemi J, McAlary M, FowlerTaylor A, et al. Tolerability of retreatment with omalizumab, a recombinant humanized monoclonal anti-IgE antibody, during a second ragweed pollen season in patients with seasonal allergic rhinitis. Allergy Asthma Proc. 2003;24(5):323-9.

52. Tsabouri S, Tseretopoulou X, Priftis K, Ntzani EE. Omalizumab for the treatment of inadequately controlled allergic rhinitis: a systematic review and meta-analysis of randomized clinical trials. J Allergy Clin Immunol Pract. 2014;2(3):332-40.

53. Verbruggen K, Van Cauwenberge P, Bachert C. Anti-IgE for the treatment of allergic rhinitis-and eventually nasal polyps? Int Arch Allergy Immunol. 2009;148(2):87-98.

54. Roberts G, Xatzipsalti M, Borrego LM, Custovic A, Halken S, Hellings PW, et al. Paediatric rhinitis: position paper of the European Academy of Allergy and Clinical Immunology. Allergy. 2013;68(9):1102-16.

55. Vashisht $\mathrm{P}$, Casale T. Omalizumab for treatment of allergic rhinitis. Expert Opin Biol Ther. 2013;13(6):933-45.

56. Kopp MV, Stenglein S, Kamin W, Friedrichs F, von Berg A, Zielen S, Hamelmann E, Wahn U, Kuehr J. Omalizumab (Xolair) in children with seasonal allergic rhinitis: leukotriene release as a potential in vitro parameter to monitor therapeutic effects. Pediatr Allergy Immunol. 2007;18(6):523-7.

57. Kopp MV, Hamelmann E, Bendiks M, Zielen S, Kamin W, Bergmann KC, Klein C. Wahn U; DUAL study group. Transient impact of omalizumab in pollen allergic patients undergoing specific immunotherapy. Pediatr Allergy Immunol. 2013;24(5):427-33.

58. Rolinck-Werninghaus C, Hamelmann E, Keil T, Kulig M, Koetz K, Gerstner B, Kuehr J, Zielen S, Schauer U, Kamin W, Von Berg A, Hammermann J, Weinkauf B, Weidinger G, Stenglein S, Wahn U, Omalizumab Rhinitis Study Group. The co-seasonal application of anti-IgE after preseasonal specific immunotherapy decreases ocular and nasal symptom scores and rescue medication use in grass pollen allergic children. Allergy. 2004;59(9):973-9.

59. Kamin W, Kopp MV, Erdnuess F, Schauer U, Zielen S, Wahn U. Safety of anti-IgE treatment with omalizumab in children with seasonal allergic rhinitis undergoing specific immunotherapy simultaneously. Pediatr Allergy Immunol. 2010;21(1 Pt 2):e160-5.

60. Agarwal R, Chakrabarti A, Shah A, Gupta D, Meis JF, Guleria R, Moss R, Denning DW, ABPA complicating asthma ISHAM working group. Allergic bronchopulmonary aspergillosis: review of literature and proposal of new diagnostic and classification criteria. Clin Exp Allergy. 2013;43(8):850-73.

61. Tanou K, Zintzaras E, Kaditis AG. Omalizumab therapy for allergic bronchopulmonary aspergillosis in children with cystic fibrosis: a synthesis of published evidence. Pediatr Pulmonol. 2014;49(5):503-7.

62. Jat KR, Walia DK, Khairwa A. Anti-IgE therapy for allergic bronchopulmonary aspergillosis in people with cystic fibrosis. Cochrane Database Syst Rev. 2013;9:CD010288.

63. Gevaert P, Calus L, Van Zele T, Blomme K, De Ruyck N, Bauters $\mathrm{W}$, et al. Omalizumab is effective in allergic and nonallergic patients with nasal polyps and asthma. J Allergy Clin Immunol. 2013;131(1):110-116.e1.

64. Ring J, Alomar A, Bieber T, Deleuran M, Fink-Wagner A, Gelmetti C, Gieler U, Lipozencic J, Luger T, Oranje AP, Schäfer T, Schwennesen T, Seidenari S, Simon D, Ständer S, Stingl G, Szalai S, Szepietowski JC, Taïeb A, Werfel T, Wollenberg A, Darsow U, European Dermatology Forum; European Academy of Dermatology and Venereology; European Task Force on Atopic Dermatitis; European Federation of Allergy; European Society of Pediatric Dermatology; Global Allergy and Asthma European Network. Guidelines for treatment of atopic eczema (atopic dermatitis) Part II. J Eur Acad Dermatol Venereol. 2012;26(9):1176-93.

65. Lane JE, Cheyney JM, Lane TN, Kent DE, Cohen DJ. Treatment of recalcitrant atopic dermatitis with omalizumab. J Am Acad Dermatol. 2006;54:68-72.

66. Vigo PG, Girgis KR, Pfuetze PL, Critchlow ME, Fisher J, Hussain I. Efficacy of anti-IgE therapy in patients with atopic dermatitis. J Am Acad Dermatol. 2006;55:168-70.

67. Sheinkopf LE, Rafi AW, Do LT, Katz RM, Klaustermeyer WB. Efficacy of omalizumab in the treatment of atopic dermatitis: a pilot study. Allergy Asthma Proc. 2008;29(5):530-7.

68. Iyengar SR, Hoyte EG, Loza A, Bonaccorso S, Chiang D, Umetsu DT, et al. Immunologic effects of omalizumab in children with severe refractory atopic dermatitis: a randomized, placebo-controlled clinical trial. Int Arch Allergy Immunol. 2013;162(1):89-93.

69. Ramírez del Pozo ME. Contreras Contreras E, López Tiro J, Gómez Vera J. Omalizumab (an anti-IgE antibody) in the treatment of severe atopic eczema. J Investig Allergol Clin Immunol. 2011;21(5):416-7.

70. Lacombe Barrios J, Bégin P, Paradis L, Hatami A, Paradis J, Des Roches A. Anti-IgE therapy and severe atopic dermatitis: a pediatric perspective. J Am Acad Dermatol. 2013;69(5):832-4.

71. Sicherer SH, Sampson HA. Food allergy: Epidemiology, pathogenesis, diagnosis, and treatment. J Allergy Clin Immunol. 2014;133(2):291-307 (quiz 308).

72. Muraro A, Roberts G, Worm M, Bilò MB, Brockow K, Fernández Rivas M, Santos AF, Zolkipli ZQ, Bellou A, Beyer K, Bindslev-Jensen C, Cardona V, Clark AT, Demoly P, Dubois AE, DunnGalvin A, Eigenmann P, Halken S, Harada L, Lack G, Jutel M, Niggemann B, Ruëff F, Timmermans F, Vlieg-Boerstra BJ, Werfel T, Dhami S, Panesar S, Akdis CA, Sheikh A, EAACI Food Allergy and Anaphylaxis Guidelines Group. Anaphylaxis: guidelines from the European Academy of Allergy and Clinical Immunology. Allergy. 2014;69(8):1026-45.

73. Lieberman JA, Chehade M. Use of omalizumab in the treatment of food allergy and anaphylaxis. Curr Allergy Asthma Rep. 2013;13(1):78-84. 
74. Leung DY, Sampson HA, Yunginger JW, Burks AW Jr, Schneider LC, Wortel CH, Avon Longitudinal Study of Parents and Children Study Team, et al. Effect of anti-IgE therapy in patients with peanut allergy. N Engl J Med. 2003;348(11): 986-93.

75. Sampson HA, Leung DY, Burks AW, Lack G, Bahna SL, Jones $\mathrm{SM}$, et al. A phase II, randomized, double-blind, parallel-group, placebo-controlled oral food challenge trial of Xolair (omalizumab) in peanut allergy. J Allergy Clin Immunol. 2011;127(5):1309-1310.e1.

76. Nadeau KC, Schneider LC, Hoyte L, Borras I, Umetsu DT. Rapid oral desensitization in combination with omalizumab therapy in patients with cow's milk allergy. J Allergy Clin Immunol. 2011;127(6):1622-4. 